\title{
Digital Transformation Designed to Succeed: Fit the Change into the Business Strategy and People
}

\author{
Daniela Robu ${ }^{1}$ and John B. Lazar ${ }^{2}$ \\ ${ }^{1}$ Alberta Health Services, Calgary, AB Canada \\ 2John B. Lazar \& Associates, Inc., Forest Park, IL USA \\ daniela.robu@ahs.ca \\ john@jblacoaching.com
}

\begin{abstract}
Digital transformation has become a necessity in our volatile, uncertain, complex and ambiguous (VUCA) world. In their 2019 report, APQC found that 75\% of organizations are undergoing digital transformation. Successful digital transformation requires a strong foundation of people, process, technology and content. Selection of the right combination of strategies and deep stakeholder engagement is important in early phases of change when transformation initiatives inform leaders and users why change is needed. Top drivers for digital transformation have business (e.g., increased efficiency and productivity) and people (e.g., optimize user experience with knowledge discovery) facets. This paper illustrates an example of digital transformation in practice led by Knowledge Management, within Alberta Health Services (AHS). AHS is Canada's first and largest province-wide, fully integrated health system with more than 102,700 employees. Employees need a platform for collaboration on projects, as well as documents and idea generation to meet business needs and enable them to become more efficient and effective in their daily jobs. The design, development, and implementation of a collaborative platform within this large organization required close orchestration of strategies, stakeholders' commitments and engagement, represented by a continuum of stakeholders' engagement formats, relationship and trustbuilding. Setting the stage for successful implementation and post implementation required a preview of technological and workforce trends to anticipate the future of work and worker. Fitting the change into overall business strategy, developing the knowledge of how change would affect the workers, and setting up a mechanism to inform leaders about adoption and user engagement were added as overarching strategies to better align with the line of sight in digital transformation. The platform was implemented with 23 business areas that expressed interest; it has demonstrated the potential to enable system transformation if implemented organization-wide. Business value was demonstrated with an ROI calculation on time savings.
\end{abstract}

Keywords: Digital transformation, system and design thinking, future of work, business value, innovation, business stewards

\section{Introduction}

Why do some digital transformation efforts succeed and others fail? Digital transformation investments will approach $\$ 7.4$ trillion by 2023 and 70\% of the organizations that invested in 2019 for digital transformation initiatives fail to pay off. That's because the majority of the organizations focus on a specific technology, rather than finding the right balance of fitting the change into the overall business strategy, developing the knowledge of how this change will affect the workers, and setting up a mechanism to inform leaders about adoption and user engagement.

In the design and implementation of digital platforms, best-practice organizations demonstrated exceptional performance by employing strategies, governance models, knowledge flow processes and technologies.

Conducting a study to review and compare seven best-practice organizations, we have learned that each defined their strategy based on the organization needs. For example, Accenture developed KM Social Learning to enable employees to learn from each other through collaboration and knowledge sharing to bring best to the clients. US Department of State considered e-Diplomacy as strategy to enable employees to tap into existing knowledge, leverage experience and expertise within the organizational and regional boundaries, find news ways to connect, collaborate, find and share knowledge anytime, anywhere. KRAFT's strategy, Knowing what we know, enabled employees to capture and transfer knowledge in order to increase efficiency, improve decision making and avoid unnecessary reinvention. WIPRO, developed a 5 S Strategy: Simplify, Standardize, Segment, Secure, Sustain, where employees are involved to deliver innovative solutions through collaboration, knowledge exchange across departments, functions, locations ensuring there is value in the knowledge being created and measuring KM's impact on the business and its customers. 
A technology analysis (applications in clinical or corporate domains, geographically dispersed teams, intranet/extranet, size of the organization, document management solution, etc.) was completed, studying seventeen organizations that successfully implemented digital initiatives. It concluded that SharePoint, integrated with different, other tools and technologies, was mainly used to respond to organization needs. Once the strategy was defined, a program was set up, and each best practice organization built their processes and frameworks to identify, capture, transfer, and manage application and use of critical knowledge. The study concluded that across the best practice organizations, similar success factors could be identified: sponsorship from senior leaders; partnership with Human Resources, IT, and Communication; strategy designed to address pain points; focus on people by enabling reward systems; and gamification. See Figure 1.
Legend:
Sponsorship
Strategy \& partnership
Benefits \& rewards for people

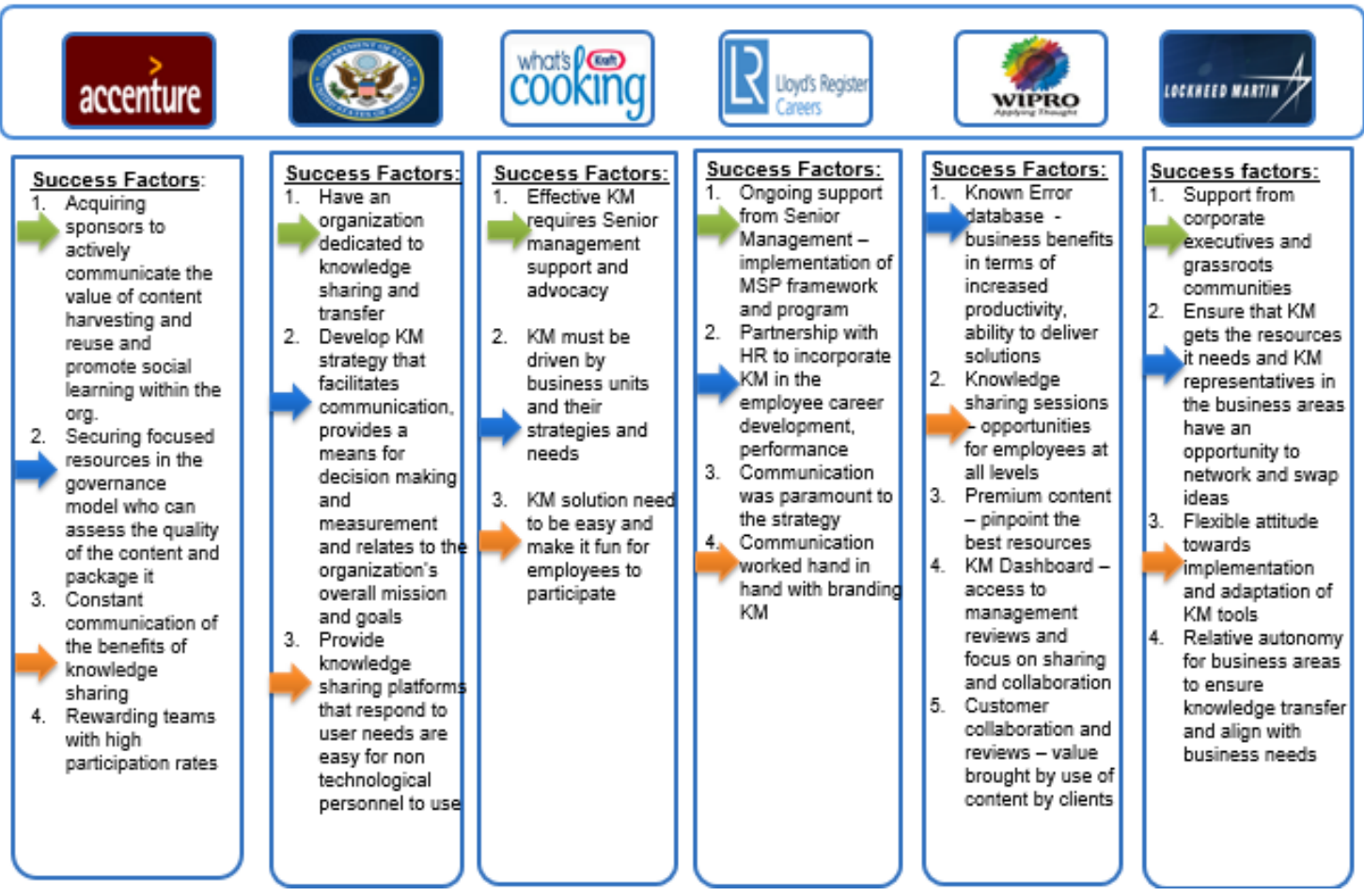

Figure 1: Best Practice organizations: Success factors for implementation of digital transformation initiatives

In this paper, the aim is to demonstrate the value of applying lessons learned from best practice organizations. This includes adopting and adapting strategies, models, and frameworks effectively used in other contexts, then using them in your organization's context. That's the path taken by AHS, described below.

We have discovered that among the variety of variables to consider when designing a digital transformation, organization maturity has proven to be critical. Other components (culture, process management, integration of people, process and technology, knowledge flow) become enablers to drive performance excellence. See Figure 2. 


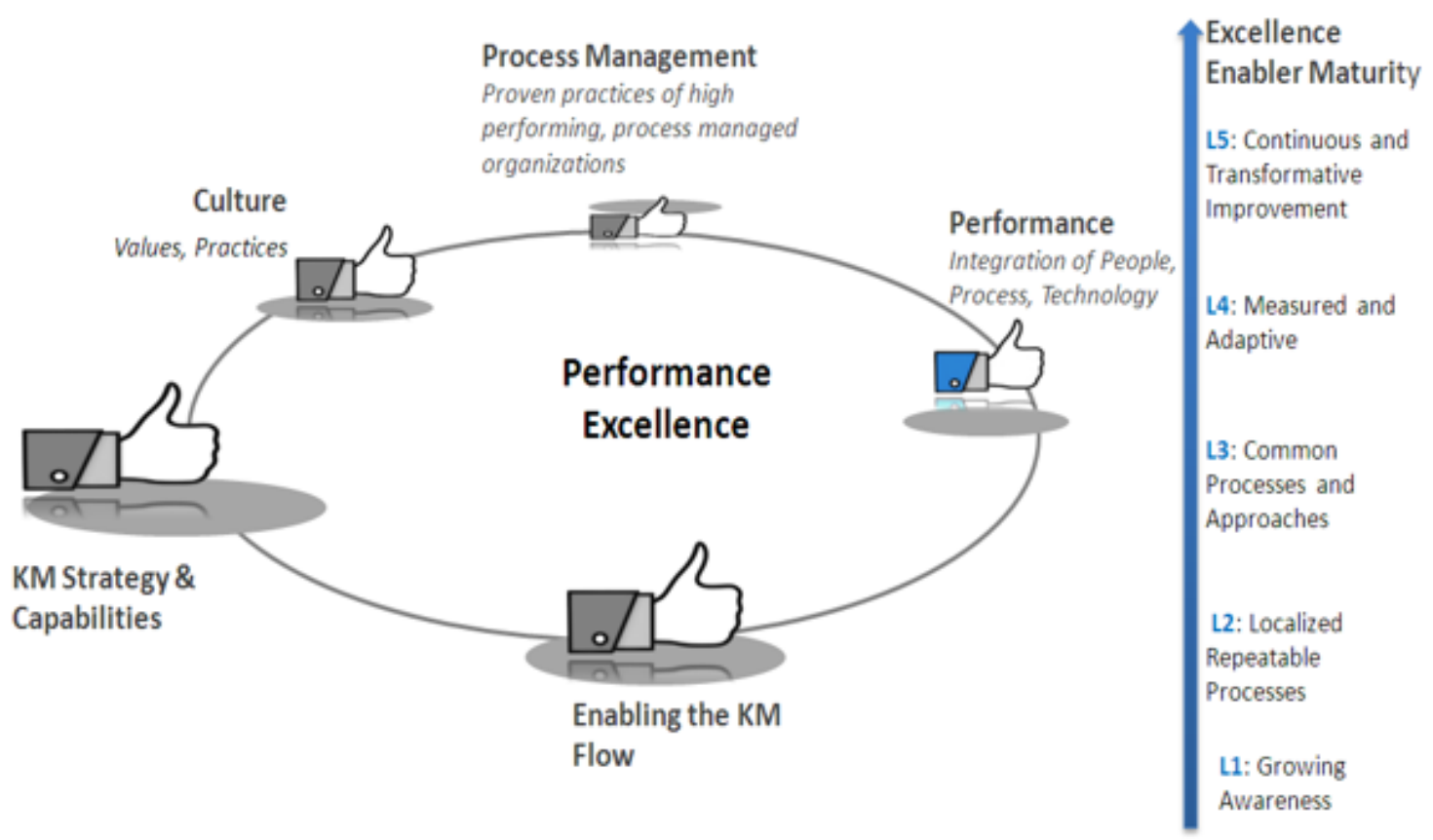

Figure 2: Knowledge management maturity level connected to performance excellence in organization

Collaborative Sites (CS) were designed with several factors in mind: organizational maturity, best practices, lessons from this study about conditions for success, and what technologies would fit and meet requirements. A range of approaches, frameworks, and applicable models is illustrated.

\section{Background}

As organizations implement digital technologies, the nature of work across industries and in organizations is rapidly transforming. Integrated digital platforms are changing where employees get work done and how they share information and learn together. These changes include digitizing data and information, automating processes, applying analytics, and enabling digital interactions.

The question is: Are employees ready and enabled? While some digital transformation initiatives involve only back-end IT work, the majority impact the employee experience in some way. Organizations need to manage expectations for the new ways of doing work and help people through it; otherwise, the experience may be negative. Of course, digital work does offer many positive benefits for employees, such as less time spent on repetitive tasks, better outcomes on document collaboration and sharing of expertise, and integrated online spaces for project work. To enable employees to quickly find the information they need, it is essential to improve findability and usability.

The other question is: Are organizations ready to handle 'the express train' of content overload? Organizations need to find ways to respond to employees' needs: 'Give me what I need, when I need it,' 'User friendly search and find,' 'Critical, relevant and up-to-date results.' Similar to the world of Formula 1 racing, every second counts in health care as well. Digital work is becoming the norm in the day-to-day work for the employees of AHS and the same questions need to be answered.

Healthcare is risk averse, implementation of digital transformation initiatives that disrupt the way employees do their daily work requires careful orchestration. What is the best way to mitigate the risk and find the right balance to lead digital business transformation and deliver financial results? Designing a roadmap to describe and understand the connection with business strategy, resources, and people required to plan and execute an effective digital business transformation initiative is essential. The design is informed by a toolkit of reviews of models, concepts, best practice organizations and their approaches, and is adapted in the context of the organization.

Fitting the change into the overall business strategy starts with talking to senior leaders, asking them about their business priorities and desired outcomes. The information collected about knowledge flow, what the 
organization measures today, leads to the goal of determining what is important, such as reducing response time to business opportunities, reducing errors, identifying subject matter experts, and assigning people on project more quickly. The tools and approaches implemented by the digital transformation team should be consistent with the business drivers, strategy, and resources; appropriate measures should be identified at this time. Qualitative and quantitative measures require a data collection system set up with methodology, technology, and data sources (HR, finance, participation and satisfaction, participation in social networking activities, content, text, and sentiment analysis). A step that is usually missed, but very important for continuous improvement and adoption, is to check after implementation with the business leaders to discuss the findings and jointly determine strategies to increase adoption of the change.

- A business engagement loop identified by the Knowledge Analytics SM Process (Toolkit 1) guides the KM professionals to align KM approaches with key business drivers and measures.

Organizational change is difficult. The analysis of complementarities can provide insights into organizational dynamics. For example, "even when senior executives have a clear vision of a new strategy for a company, managing the change can be difficult or impossible" (Argyris, 1982; Schein, 2004, Siggelkow, 2002).

Complementarity is an important concept in organizational analysis, and it is based on studying the interactions among pairs of inter-related decisions. If a company is evaluating a trio of decisions: "1) Whether to adopt a strategy that requires implementing frequent changes in its technology, 2) Whether to invest in a flexibly trained workforce, and 3) Whether to give workers more discretion in the organization of their work, the

- Matrix of Change can be used by leaders to assess the feasibility, scope, rhythm and unit of organizational change efforts" (Brynjolfsson, Renshaw and Van Alstyne, 1997). (Toolkit 2)

Developing the knowledge of how the change will affect the workers - "From Gartner's perspective, 'the transformation journey is taking large enterprises especially at least twice as long and costing twice as much as they originally anticipated.' In large part this is due to cultural readiness, "53\% of the organizations surveyed remain untested in the face of digital challenge and their digital transformation readiness therefore uncertain" (Gartner, Inc., 2020). Cultural readiness is usually connected to the organization's digital business maturity which assesses the readiness for change and understands the required critical capabilities and competencies.

- $\quad A P Q C^{\prime}$ 's Levels of Knowledge Management Maturity ${ }^{S M}$, presents a roadmap for moving from immature, inconsistent knowledge management activities to mature, disciplined approaches aligned to strategic business imperatives (Toolkit 3).

Explaining 'why' the change is needed and creating captivating stories that detail the impact of the transformation and what are the benefits for the workers are also required to succeed in the implementation of a digital transformation initiative.

- Communication strategies with promotions and regular updates are part of the change strategy (Toolkit 4).

New processes are to be developed with input from users during pilots and proofs of concepts. Assessing the critical changes is required for setting up an infrastructure that can facilitate and support new digital business models. Continuously learn from best practice organizations that embed KM digital transformation programs, tools, and approaches into critical business processes and workflows.

Putting Knowledge in the Flow of Work Best Practice Study), presents how organizations like Alcoa World Alumina, MWH Global, Nalco, NASA, and Tata Chemicals have integrated knowledge sharing and collaboration into every aspect of their operations, creating a work cadre that are hardwired to collaborate and share what they know.

- Introducing the change into the flow of the work (Toolkit 5) incorporated knowledge-sharing behaviours in the worker performance goals and discussions. It also motivated the employee on a personal level to be recognized for subject matter expertise and career advancement.

Setting up a mechanism to inform leaders about adoption and user engagement - American Productivity Quality Centre (APQC), identified five organizations as "best practice": EY, MetLife, MWH Global, Nalco, and Wipro Ltd. These organizations focus their measurement efforts on assessing employees' level of engagement with available content as well as the overall user experience. 
- Connecting People to Content Best Practice Study (Toolkit 6), reported that the top-rated health measure among best-practice organizations is the number/percentage of employees accessing content, which two-thirds consider effective to evaluate content tools and initiatives. In addition, half the partners find it beneficial to conduct surveys in order to gauge employee satisfaction with content and systems.

Business will continue to transform. As we look into the future, we have to think of the transformation as a benefit, not a threat, and ask ourselves questions differently: Instead of "What technology is doing to us?" consider "What we will do with technology?" Instead of "It is an inexorable trend!" Consider "It's a powerful tool." And instead of "It's an inevitable outcome." consider "It's a product of our choices."

- MIT, Digital Business Strategy: Harnessing our Digital Future, 2020 (Toolkit 7).

The IDC FutureScape webinar and research series for 2021 draws one clear conclusion: technology will play an even greater role in getting us all to the next Normal. Four major developments are listed:

"Acceleration: Identifying where the crisis and enterprises' responses are accelerating existing IT trends;

Remediation: Identifying where enterprises will focus investments in the next two years to remediate shortcoming in existing IT environments exposed by the crisis as well as shortcomings introduced during initial emergency responses; Extension: Identifying where enterprises will seek to leverage technologies to take advantage of competitive and industry disruptions and extend their capabilities in the new normal and Ecosystem Transition: Identify how enterprise responses to the other three developments will alter the IT industry ecosystem itself."(IDC, 2021)

Designing the roadmap for digital transformation next includes three specific steps. In addition, an ongoing reference to the future of work and how trends are positioned should be factored in. See Figure 3.
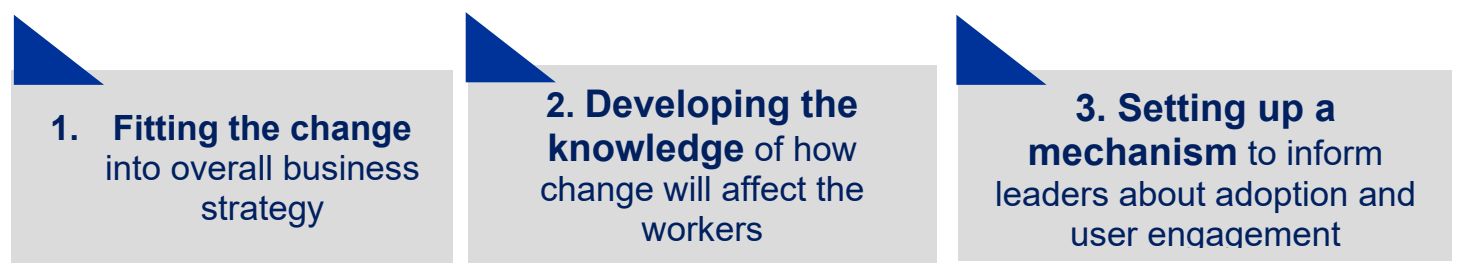

Align with future of the work and trends: Acceleration, Remediation, Extension, and

Figure 3: Roadmap for Digital Transformation

The roadmap augmented by the Toolkit of concepts, models, and best practices position organizations (in particular, healthcare) in better shape to succeed in digital transformation initiatives.

In 2016, the Knowledge Management (KM) team within AHS, in collaboration with IT and Web Communication, was tasked to determine if AHS-licensed technology met the current organization needs for information and knowledge management. In the same year, a project designed to answer this question was commenced. The design of the project was informed by prior consultation with leaders and technology end users to identify and prioritize pain points. It was also important to have a common understanding of the terms that were used for collaboration, engagement, access, etc. A key discussion for stakeholders' buy-in was to clearly explain the 'why' and 'how' digital transformation could contribute to strategic business priorities and talent management goals.

This pre-project phase primed the right foundation in terms of people involvement and interest, and implicitly supported the need for a well-defined structure and process for the project moving forward. One year into the future, the output was defined, and the project team would deliver an online platform that integrated technology tools (SharePoint and Tableau) that responded to business needs (reflected in activities to access, engage, collaborate, manage and monitor) as identified by the stakeholders. The intent was to implement the project product on a trial basis for use by interested end-users and evaluate outcomes and ROI of the digital transformation experience for these end-users.

During the project phase, engagement had a significant importance as three layers needed to be balanced: within the project team members, the first cross-functional team of this nature in AHS (with expertise from KM, IT, Web Communication); between project team members and stakeholders; and between project team 
members and sponsor. Deep engagement starting in the early phases of change helped ensure processes were optimized and people were ready to embrace the benefits of digital transformation. Maintaining the stakeholders' interest during the project was possible by employing an Agile project management methodology that frequently required their input in product development. The sprints were designed to respond to the pain points (e.g easy find and search, improved document, meeting, project management and more engagement tools) identified by users. With this approach, the output, named Collaborative Sites (CS), was ready for implementation in the business areas represented by stakeholders. See Figure 4.
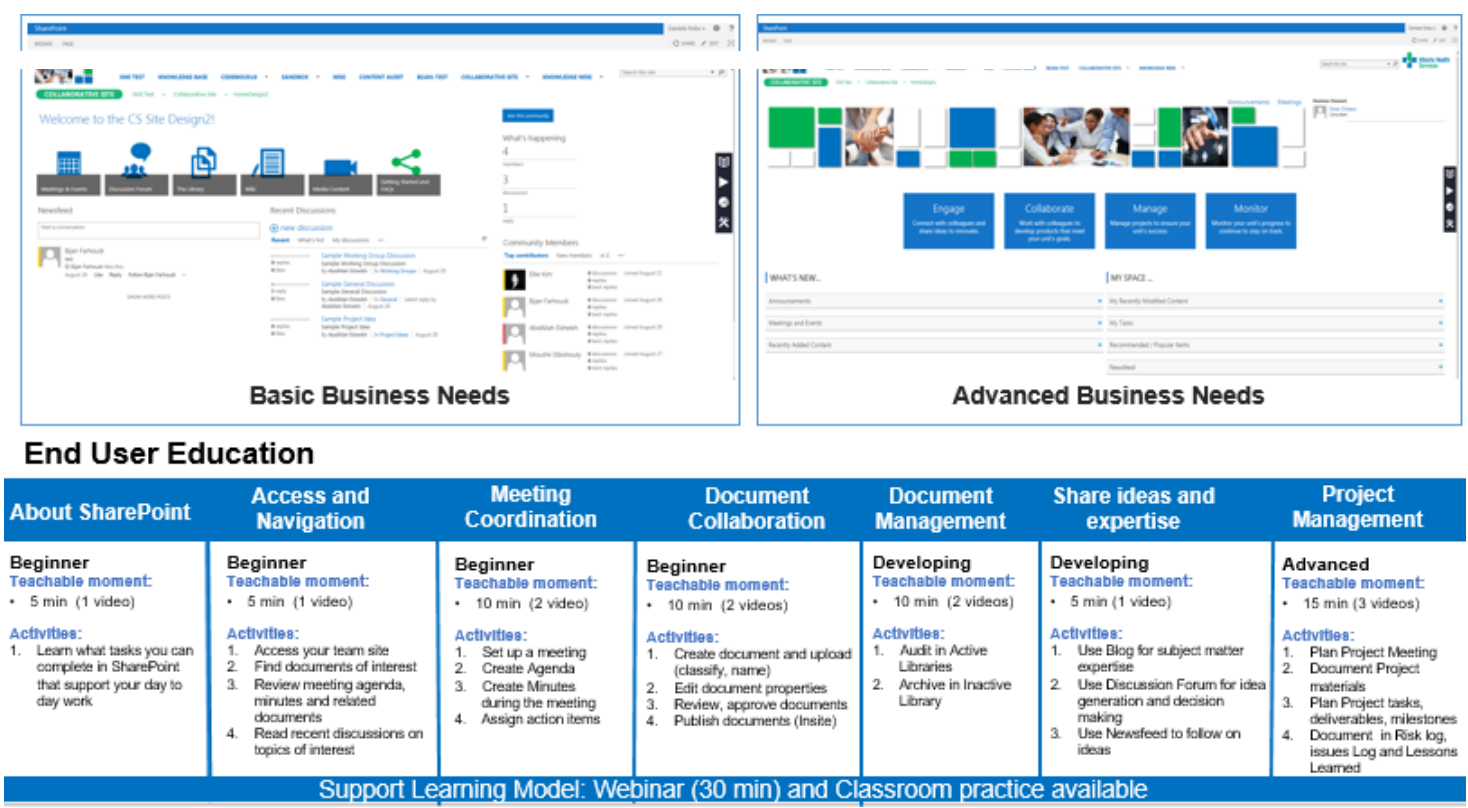

Figure 4: Collaborative Sites

This next phase, transitioning from project to operations, required different engagement strategies. Leading a Collaborative Site implementation in the flow of the work required engagement of employees through effective communication about change while cultivating the skills and capabilities they needed for future success. Leaders also played a significant role in the implementation process. Knowing the priorities of their business areas and the user's maturity level from digital capabilities perspective, they carefully designed how to bring the new ways of completing their day-to-day work. Different implementation designs were deployed: phased implementation of functionalities (e.g., start with document management followed by meeting and project coordination), phased training for user groups (e.g., start with leadership followed by end-users) or full implementation of functionalities and training in the same time with a cut of date from old ways of doing their jobs.

Post-implementation phase highlighted different needs for users and business. It became evident that in addition to document, project and meeting management, each business area had specific processes (e.g., request log to capture intakes, operations log to assign tasks, education needs, repository of questions that require analysis, etc.) that guided their operations model. As users started to use the functionalities and resources provided to support their learning, different training requests were identified.

The evaluation and analysis of Collaborative Sites adoption, usage, efficiency, and quality required the selection of the most responsive Blended Solution (one or multiple interventions that address the same root cause). Content management lifecycle processes required attention as the number of documents created increased exponentially (e.g., audit and archive solutions needed to be designed and implemented). See Figure 5. 


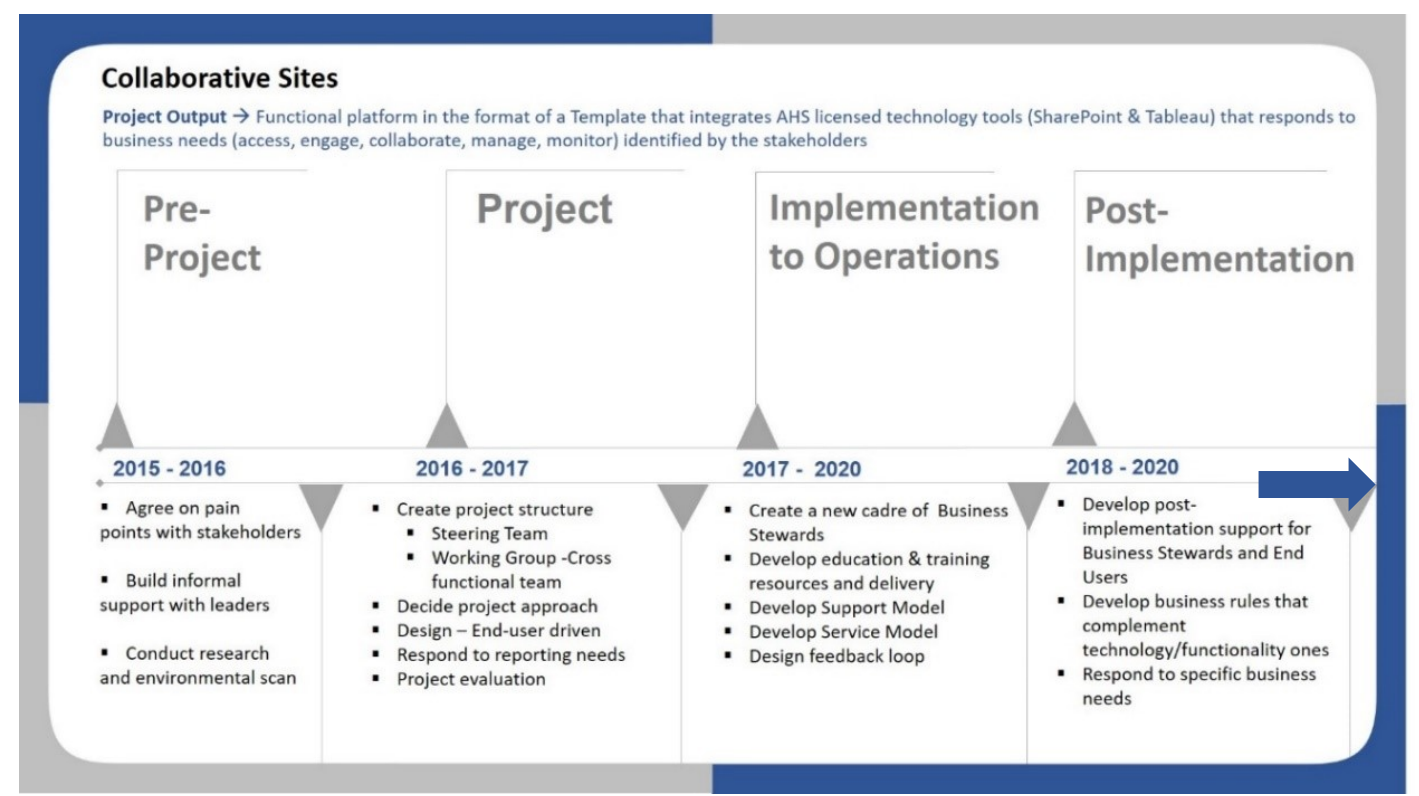

Figure 5: Collaborative Sites Phases

Successful digital transformation requires a careful orchestration of the following components: technology, people, process and content. This implies the design and deployment of different solutions, approaches, models, and methodologies at every stage. "True transformation will engage all, and will require tools, techniques and approaches to involve all in the proposed reforms" (Dickson \& Lindstrom, 2010, p. 20).

\section{Methodology}

Digital transformation initiatives require future thinking and when selecting the methodology, the organizations need to consider where they want to be in three years from the moment of implementation, what business value the initiative will bring, anticipate the technology progress, predict dynamic changes in business priorities, and prepare employees for the future of the work. In order be well equipped with evidence for the approaches that were applied, the following steps were completed:

- Environmental scan that included a study of best practice organizations that were successful with the implementation of digital transformation initiatives (e.g., Accenture, Kraft Foods, US Department of Defense, Lloyd's Register, Lockheed Martin, Wipro) - comparing the strategies, processes, people and content that they have selected to respond to their organization's vision, mission, value (Data collection: Literature review, synthesis; Format: Report)

- Interviews with stakeholders represented a key step in informing the CS design and sprint planning. Thirteen departments were selected based on their interest in knowledge and information management, service needs, expertise, experience with use of technology, influencers in the organization. Thirty representatives were identified by department leaders. Eight focus groups (3 Strategic Clinical Networks, Health Information Management, Policy, Primary Care, Clinical Knowledge Content Management, Knowledge Management), were organized to gather details of the business requirements. Each focus group was equipped with the same Business Scenario template (included: scenario name, background, goals, desired outcomes, role/persona, stakeholders, process), and the activity during the focus group was to capture the story of their current processes and pain points for major initiatives and inform what their vision is for the future. The result produced eight complex business scenarios. The functions and processes identified from scenarios were grouped in common and specific business needs across the interviewed areas and captured in a checklist which represented the basis of the CS platform desired functionalities:

- Project/Initiatives: a place in the platform where leaders can have a view of the numerous projects and initiatives, connected to goals to allow opportunity to inform decision making

- Document Collaboration: one-stop shop for clinical knowledge content, clinical, and corporate policy aligned with the content flow from creation to publication; structured place for educational materials

- Engagement: enable social media tools to allow patients, universities, health care professionals to share stories and expertise 
- Reporting: ability to have three layers of reporting, strategic, tactical and operational, analytics for site activity and content contribution

The consensus from all focus groups was that all the above activities required creating a global lessons learned repository, reference libraries, best practice repository, and expertise locator space

- The analysis (Data collection: Interview checklist; Format: knowledge maps and database) - (APQC, 2018)

- Review of proven and emerging knowledge management approaches implemented in organizations and the impact of their implementation (Data collection: Literature review and synthesis; Format: Presentation)

- Frameworks integration to cover requirements both from performance and healthcare environment perspective (Data collection: Study analysis; Format: Integrated framework diagram)

- Agile Project Management Methodology - rigorously designed to meet the requirements related to project information creation, storage and sharing (Data collection: Site with tools for document, task, meetings, and risk management; Format: SharePoint site)

- Education models applied such as ADDIE (Assess, Design, Develop, Implement, Evaluate) and adult learning principles for reinforcing knowledge acquisition and reinforcement (Data collection: Objectives, learning activities, knowledge checks; Format: Curriculum) (APQC, 2020)

- ROI (Return on Investment) evaluation methodology to capture employees' reaction, application, business impact and consequently ROI calculation for time savings (Data collection: Surveys; Format: Graphs with trends of employees' adoption of new knowledge over time) (Phillips, Phillips, Stone \& Burkett, 2007)

- Review measures to capture user engagement, CS use and adoption and process efficiencies (Data collection: Review of best practice organizations that implemented knowledge management systems; Format: Presentation)

- Review content management best practices (e.g., processes, procedures, technology, tools) implemented in organization and related audit policies (Data collection: Review of best practices, models to identify critical, relevant, and up-to-date content, frameworks; Format: Reports, publications (APQC, 2013, AlIM)

- Review change management models (strategic level: 7S model; project team: ADKAR model, users: ADKAR and Kotter/Lewin model) that are to be applied across the continuum of the initiative from preproject to post-implementation

\section{Collaborative Sites Platform}

\subsection{Innovation and System transformation}

\subsubsection{Fitting the change into overall business strategy}

The Collaborative Sites (CS) journey required system thinking and systematic approaches to advance from innovation to system transformation. A non-conventional approach was considered to address the complexity of this type of initiative in healthcare. Two frameworks - LEADS (Lead self, Engage others, Achieve results, Develop coalitions, System transformation; Dickson \& Lindstrom, 2010) and HPT (Human Performance Technology; Van Tiem, Moseley \& Dessinger, 2012) - were integrated. See Figure 6. 
LEADS Framework

LEADS in a Caring Environment provides a customized For Health, By Health Canadian framework for responding to this growing need for a concerted, coherent, and sustainable strategy for strengthening Canada's health leadership capacity.

The framework features five domains: Lead Self, Engage Others, Achieve Results, Develop Coalitions, and Systems Transformation. Each of these five domains consists of four core, measurable capabilities

https://www.leadscanada.net/site/fra mework

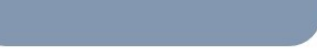

HPT

Human Performance Technology
HPT Framework

HPT Framework - Gaps and root causes that hinder expected results and performance (e.g., business processes, knowledge flow, decision making) can be identified and prioritized; solutions can be selected, designed and delivered to positively impact learning, performance and business results

Van Tiem, Moseley, \& Dessinger (2012)

Figure 6: System Transformation: Concept - Integration of LEADS and HPT Frameworks

LEADS in a caring environment framework was integrated with the HPT framework to assist in two ways: identifying the intersection of different domains (Change Management, Knowledge Management and Performance Improvement) and selecting the best Blended Solution (BS) for the Collaborative Sites during the project and implementation in operations. A Blended Solution is distinctive (Lazar, Greenblatt, \& Robu, 2017) in that it will likely:

1. include one or more simultaneous, integrated, interdependent, synergistic Interventions;

2. address the same root cause(s) redundantly;

3. require both qualitative and quantitative measures to design and measure effectiveness;

4. align multiple stakeholders; and

5. require faith, courage and stretch.

\subsubsection{Steps from Innovation to Implementation}

Many organizations dive into digital transformation initiatives without taking the appropriate steps to prepare for transformation. Also, a different mindset is required when it comes to the expectations for employees' performance - they must learn and apply new knowledge while executing (Edmondson, 2008).

How did we achieve performance excellence as a result of digital transformation?

Thirteen steps were considered in the Collaborative Sites initiative (see Figure 7). By integrating the LEADS framework with the HPT one, we ensured that in each phase of the initiative - pre-project, project, transition from project to operations and post-implementation - system transformation capabilities were linked to desired performance outcomes. 


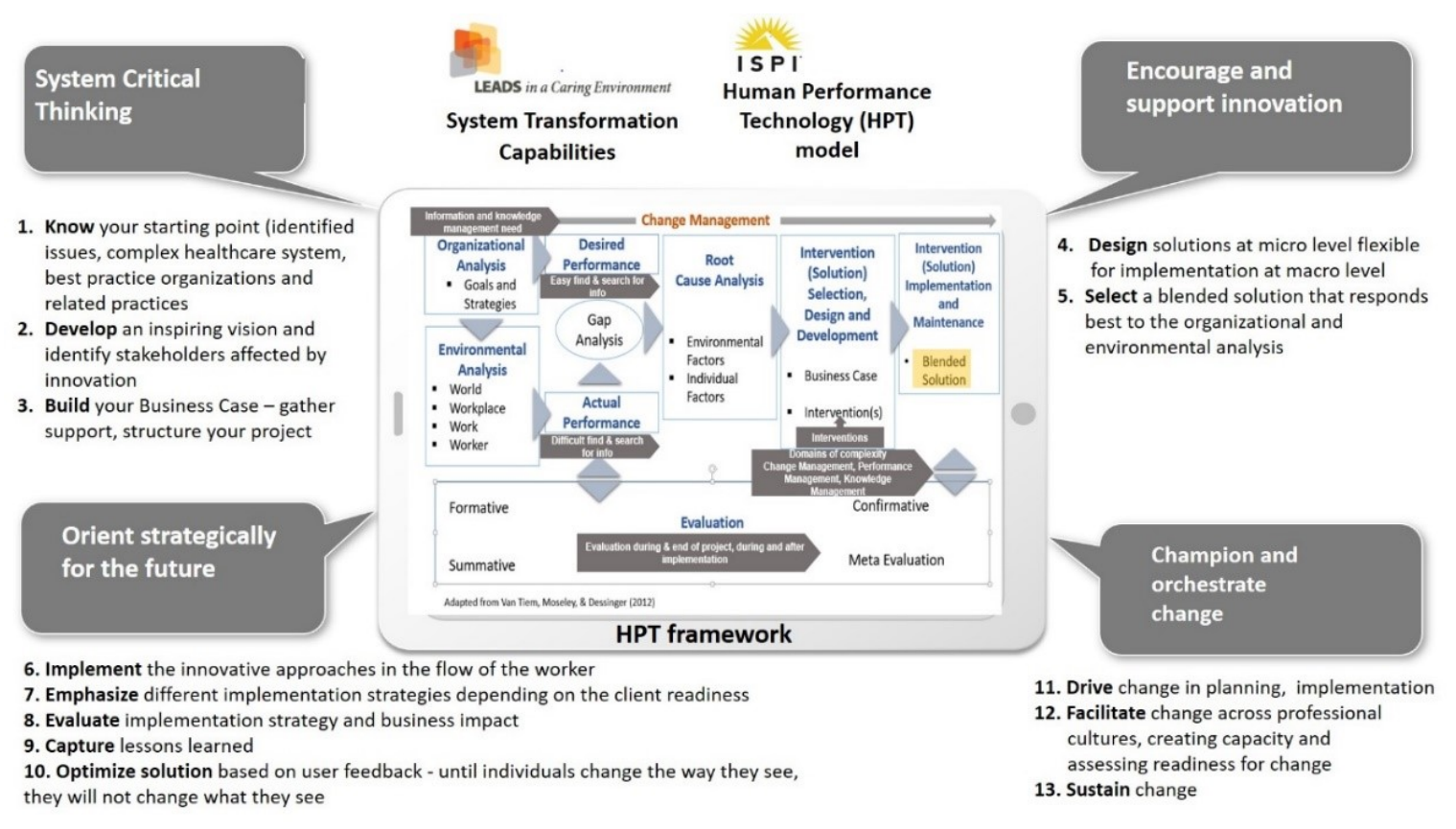

Figure 7: Innovation to System Transformation: Thirteen Steps

One question that has to be answered is how all these frameworks and methodologies really work together. In other words, how do they best blend to be integral parts of the solution and respond in the best way to the desired outcome. The following details attempt to demonstrate in a practical way how they were considered and used in the Collaborative Sites example.

1. Pre-project Phase - System Critical Thinking capabilities

Know your starting point (identified issues, complex healthcare system, best practice organizations and related practices) was designed with attention to stakeholder engagement by inviting them to participate in knowledge mapping. This is one of the most powerful knowledge management approaches to identify and understand the organization's critical information and knowledge management needs. The mapping clearly explained the "why" and "how" so that stakeholders understand how it contributes to business goals. This also helped with the identification of the pain points we needed to address with CS - Improved functionalities and tools for: access navigation, user interface, engagement, collaboration, and management tools as well as My Space, an individual area that brings forward all the documents, action items and discussions that the employee was involved with (Step 1).

At this point, stakeholders could start to see the potential of the change and an important next step was to develop an inspiring vision and identify all the stakeholders affected by innovation. The best approach to continue to maintain the interest was to develop a prototype that showcased possible outputs of technology and how they responded to the pain points (Step 2).

Momentum was built and stakeholders were ready to support the next step of building the business case and structure the project. Governance for the project was determined by identifying the Sponsors (KM, IT), crossfunctional Project Team (IT, KM, Web Communications, Identity Access Management) and Steering Team (participation from 13 departments). A project charter was prepared, and Agile Project Management Methodology adopted (Step 3).

These three steps are anchored in the HPT framework that relate to organizational and environmental analysis, present the gap between actual and desired performance, and identify root causes both at individual and environmental levels.

2. Project Phase - Encourage and support innovation

Future of digital work requires leaders to think how they balance the ratio between what technology does and what the worker does, how their business models change, and design solutions at the micro level flexible for implementation at the macro level. Engagement strategy again played a very important role and required three 
layers of approaches: business stakeholders were invited to test prototypes and provide feedback on how well the functionalities responded to the identified gaps (five Agile sprints were planned and 16 prototypes refined, based on user feedback); cross-functional team brainstormed and developed different modalities to respond to the needs and regular check-ins with stakeholders provided design course-correction; Sponsors were deeply involved in ensuring the solution put forward met the agreement of all the stakeholders involved. (Step 4).

Multiple variables must be considered when designing a technological solution. It is about People and how the technology aids them in completing their day-to-day job, satisfaction and learning. This required the Project Team to select a blended solution that responds best to the organizational and environmental analysis. Technology was approached from end user-driven design in prototyping, scanning of future trends in Business Intelligence and Artificial Intelligence and integration of proven and emerging knowledge management approaches. The People side was approached from competency development (creating a Business Steward role), roles and responsibilities needed to assist with CS adoption, change management, optimization, and ongoing management of the site (Step 5).

The HPT model proved helpful in identifying the steps in the selection of interventions and prioritizing the ones that create the bundle for the blended solution.

3. Operations Phase - Orient strategically for the future

Embedding digital transformation in organizations by implementing knowledge management approaches encourages engagement by making it easier for the worker to look for, capture, and transfer knowledge in the course of their jobs. Best-practice organizations drive knowledge management further into the flow of work by incorporating knowledge-sharing behaviors in employee performance goals and discussions. With CS clients, the approach was to implement the innovative approaches in the flow of the worker. This was achieved by mapping the CS functionalities and tools to their particular business scenarios from daily activities. It was similar to setting directions on a map from point A to point Z. These scenarios were made available in a Wiki and benefits were identified for each group of functionalities. This activity made the transition easier for staff, from current to new processes (Step 6).

The implementation for this type of transformation in operations involves the cross-functional team and Sponsors. They play different roles now in comparison to the pre-project and project phases and emphasize different implementation strategies depending on client readiness. The cross-functional team now operates following a Service Level Agreement put in place to clarify roles and responsibilities for the team and the type of requests that need to be addressed during the ongoing use of the CS sites. In the Operations phase, the Sponsor is represented by the leader of the business portfolio/department/area. For them, it was important to model different implementation strategies based on their current workload. For example, some Portfolio leaders decided to implement first at the department level (core set of Business Stewards that will master the usage, then bring the rest of the users on board) or Portfolio leaders decided to implement in all areas at once (assign Business Stewards for all areas and trained in the same time). Depending on their choice, different change management, education, site development approaches were used (Step 7).

To be able to evaluate implementation strategy and business impact, an enhanced support model for workers was developed. Lessons learned from previous implementation informed us that a self-serve model was not enough for the changes brought by digital transformation. The enhanced support model included: Request Log where Business Stewards submit their asks for troubleshooting, need for more training or functionalities to support specific needs; Frequently Asked Questions (FAQs) in the format of an online list that collates the questions and answers from business areas and is grouped on topics (access, security, content, how-to's, etc.); Webinars, conducted to transfer knowledge through simulations and case studies; and Touchpoints, online classrooms to assist with skills reinforcement using job shadowing. Self-Serve tools were also made available, such as Help and Training Library with 92 resources available based on topic, type of support tool (job aid, training bite, video, guideline) and role (Business Steward, End user) (Step 8).

A lessons learned repository was built to capture insights from the training with Business Stewards and users, implementation strategies, challenges and approaches to respond (Step 9).

As business areas started to use the Collaborative Sites, different performance tools were developed for them. The set of tools included: Service Model, a document that specifies the type of changes, updates the Business 
Stewards can apply to CS or when they need to ask for support, as well as the approvals they need to obtain before applying changes; Business Rules, a document that specifies the management of the site (content audit and archive, user access and permissions, purpose of different tools, transfer of duties in case of transfers/turnover, etc.); and a Change Management Guide developed using the ADKAR (Awareness, Desire, Knowledge, Ability, Reinforcement) model to provide the business areas with a diagnostic tool and related interventions.

Training evaluation - conducted via surveys at the end of each training session, provided us with feedback on how to improve while we were provided training; CS platform evaluation - all the input provided by users was collected in an optimization list and during the first year of implementation, we addressed 40 bugs and improvements; Business impact - time savings, easy access to information were important output measures. An ROI calculation was completed for only one of the CS functionalities - meeting management. The result demonstrated that the new way of coordinating meetings was more efficient, with an ROI of $120 \%$. The analysis of the usage of these tools assisted the team to optimize a solution based on user feedback (Step 10).

HPT framework was helpful in identifying the blended solution needed during implementation and maintenance.

4. Post-implementation Phase - Champion and orchestrate change

\subsubsection{Setting up a mechanism to inform leaders about adoption and user engagement}

Significant efforts were made to start the wheel of change and the switch from current ways of doing things to the new ways. How can we sustain and scale the adoption? Drive change in planning and implementation is one important strategy. Effective adoption and engagement measures have to be designed and implemented. Adoption becomes powerful when business areas become owners of the change. Structured mechanisms to continue the adoption of CS (monthly meetings with the CS leads and Business Stewards) were put in place. In this way, they could field the type of questions and issues that arise in the user community, address and deploy different approaches to respond. Knowledge management team attended the meetings to respond and provide guidance (Step 11).

Gamification features were enabled to showcase best content, author, contributor using badges, and ratings. These features developed new behaviors in the users and increased motivation to participate and contribute and overall facilitated change across professional cultures, creating capacity and assessing readiness for change (Step 12).

To sustain change, markers of success had to be identified. Best practice organizations measure the extent to which employees are actively contributing, sharing, accessing, and reusing content. Overall engagement rates represent good indicators of health since workers are likely to participate only if the tools are ready to use and content provides a tangible benefit (Step 13). In the CS instance, the analysis of the markers of success continuously informed us what the users needed to optimize in their flow of work. Examples included:

- Request log analysis identified thirteen specific needs that needed to be addressed for different business areas by building solutions to enable efficiency in operations (e.g Educators Hub, Operations and Tracking Log, Project Management Wiki, Course curriculum, registration and management, Research libraries, etc.)

- User Survey analysis identified the need to redesign the Help and Training resource to improve search and find based on user's feedback after 1 year of implementation (Categories: user's roles and group of resources, such as governance, document, project and meeting management)

- Request log analysis informed the implementation team on the type of requests and how to organize themselves in order to become quick in response and follow up actions. The analysis showcased that technical support was the top on the list, followed by education, access issues and enhancement requests

- Education needs analysis required the creation and delivery of an education offering focused on document organization

- Enhance the CS analytics to inform users and leaders about the usage of the site (storage, size of files, types of files). Dashboards and a Content Audit Guide with tools and checklist were developed to assist users in deciding which content to keep in the sites that is critical, relevant and up to date. See Figure 8. 
Confirmative, meta-evaluation and communication plan elements from the HPT framework were applied in this context.

\section{Content indicators}

Is your content critical, relevant and up-to-date?

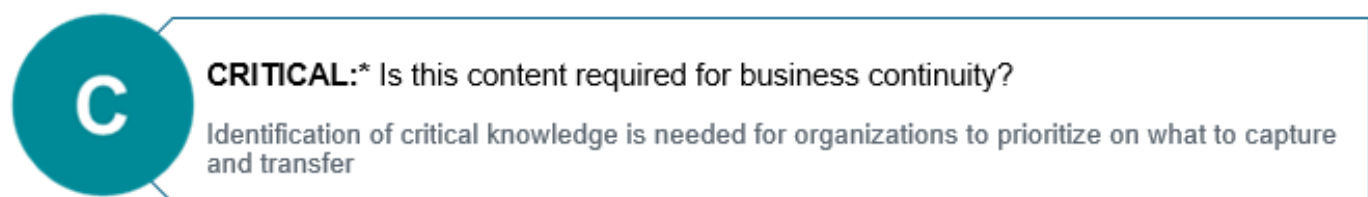

RELEVANT: Is the content related to the current business operations of my
department?
$\begin{aligned} & \text { Not all content is created equal or has the same value; thus, content relevancy helps } \\ & \text { segregate knowledge asset from information noise }\end{aligned}$

UP-TO-DATE: Does it reflect the current operations including the activities, services
and projects we are working on?
Once content has been identified as critical and/or relevant then it is imperative that content is
kept up-to-date so that it can be relied on as a trusted resource

Figure 8: Content indicators that trigger audit actions

To sustain change, leaders and users need tools that measure and present in a snapshot the activities in the site at individual, tea, and department level. A content and web analytics framework was developed to respond to the leadership needs to visualize the status of the CS implementation in their areas (see Figure 9). A set of measures were identified to emphasize user adoption and participation, efficiency and quality, engagement and satisfaction.

\section{Adoption and participation}

Efficiency and quality

Engagement and Satisfaction

\begin{tabular}{|c|c|c|c|c|c|c|c|c|c|c|c|}
\hline \multirow[t]{6}{*}{ Value } & \multirow{6}{*}{ 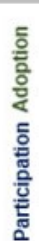 } & Users & \multirow[t]{6}{*}{ To date } & \multirow[t]{6}{*}{ Value } & \multirow{6}{*}{ 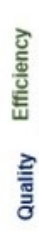 } & $\begin{array}{l}\text { Time to find } \\
\text { oontent }\end{array}$ & \multirow[t]{6}{*}{ To date } & \multirow[t]{6}{*}{ Value } & \multirow{2}{*}{\multicolumn{2}{|c|}{ 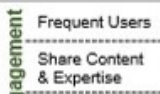 }} & \multirow[t]{6}{*}{ To date } \\
\hline & & Views & & & & Searches $(0)$ & & & & & \\
\hline & & Documents & & & & Searches $(+)$ & & & 总 & $\begin{array}{l}\text { Most Popular } \\
\text { Content \# }\end{array}$ & \\
\hline & & Rate creation & & & & Critical & & & 들 & Expertise & \\
\hline & & Downlogds & & & & Relevant & & & 可. & Reoognized & \\
\hline & & Contribution & & & & Up to date & & & कू & $\begin{array}{l}\text { Content seen } \\
\text { as Valugble }\end{array}$ & \\
\hline
\end{tabular}

Figure 9: Business Value: Content and Web Analytics Framework

Dashboards and Information Sheets on how to interpret and intervene were developed and launched to the CS users after 2 or 3 years of implementation. For each measure, for example, "Adoption", the Information Sheet included details on: How do I interpret the data? Trends; How do I intervene to course correct? This became a handy diagnostic and treatment tool for leaders to decide the best path forward to improve adoption of digital tools.

\subsection{People: Business Stewards Program}

\subsubsection{Developing the knowledge of how the change will affect the workers}

A role called Business Steward was created to aid implementation of the technology (Collaborative Sites), ensure effective management of individual SP sites, and reinforce best practices. Online education and performance support tools were offered to increase their adoption and use. Business Stewards represented the direct connection between the business area (leaders, owners, end users) and Knowledge Management Team.

Their responsibilities are to: champion CS uptake; master CS functionalities (45 functionalities related to the engagement, collaboration, management of meetings, projects and reporting) by completing six training webinars; follow continuing education and training offerings; train team members (end users); follow the CS 
Service Model to inform what requests; approvals are to be in place for changes to the CS; contribute to the evolution of the CS and works across teams for consistency; communicate with leads, owners about changes or newly identified needs; use the CS Education and Training resources; administer user access to the C; maintain $\mathrm{CS}$, auditing site from content and access perspectives.

Business Stewards needed to be equipped with new knowledge and skills for the digital workplace. As Business Stewards learned new skills while completing other jobs for their role, which we call knowledge above the flow, a gradual learning path was developed to assist with easy learning and application (see Figure 10).

The training was divided by timing of delivery: during CS implementation with two layers of complexity (awareness and intermediate), and after CS implementation when the Business Stewards have learned how to use the functionalities and now are ready to accumulate more skills on how to manage the CS (advanced).

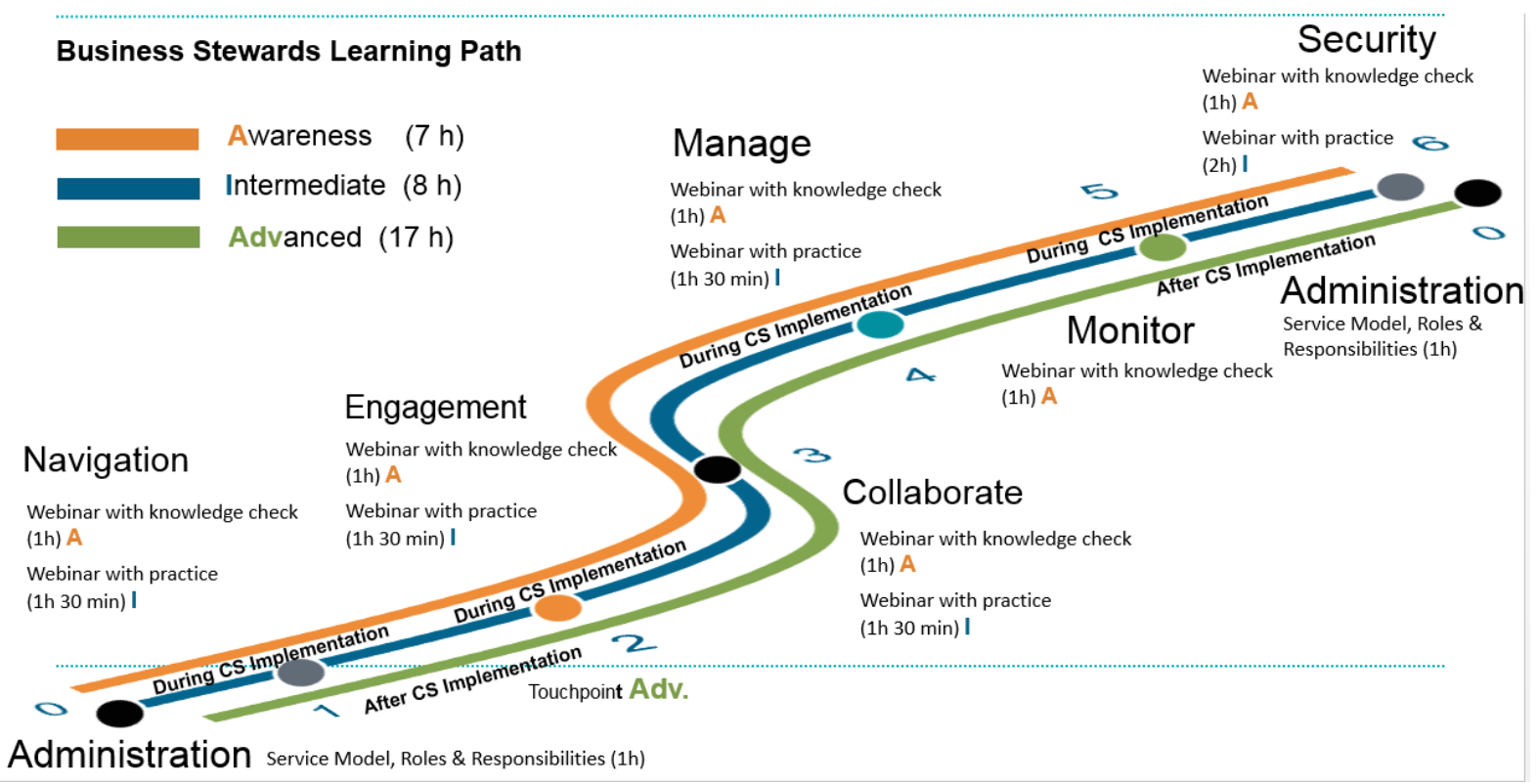

Figure 10: Business Stewards Learning Path

Upon completion of the modules (Administration, Navigation, Engagement, Collaborate, Manage, Monitor, Security), the Business Stewards received a Certificate of Achievement that highlight their enhanced capabilities in digital work.

\subsection{Technology: Knowledge management approaches integrated in functionalities}

The AHS information and knowledge management need was addressed by analyzing best practice organizations and implementing relevant knowledge management approaches that made sense in the context of the organization: demonstrated business value, increased people engagement and enhanced collaboration. A mapping was completed to connect the pain points identified by the stakeholders (need for more engagement, sharing, collaboration, management and monitoring tools) to proven (e.g., lessons learned, knowledge base, Communities of Practice, etc.) and emerging (e.g., Ask the expert, newsfeeds, analytics-dashboards) knowledge management approaches (see Figure 11). Technology features were aligned to develop the tools that covered these approaches. Twenty knowledge management approaches are embedded within CS (7 proven, 13 emerging). This ratio also indicated the need for a concerted effort for both education/training and change management. 


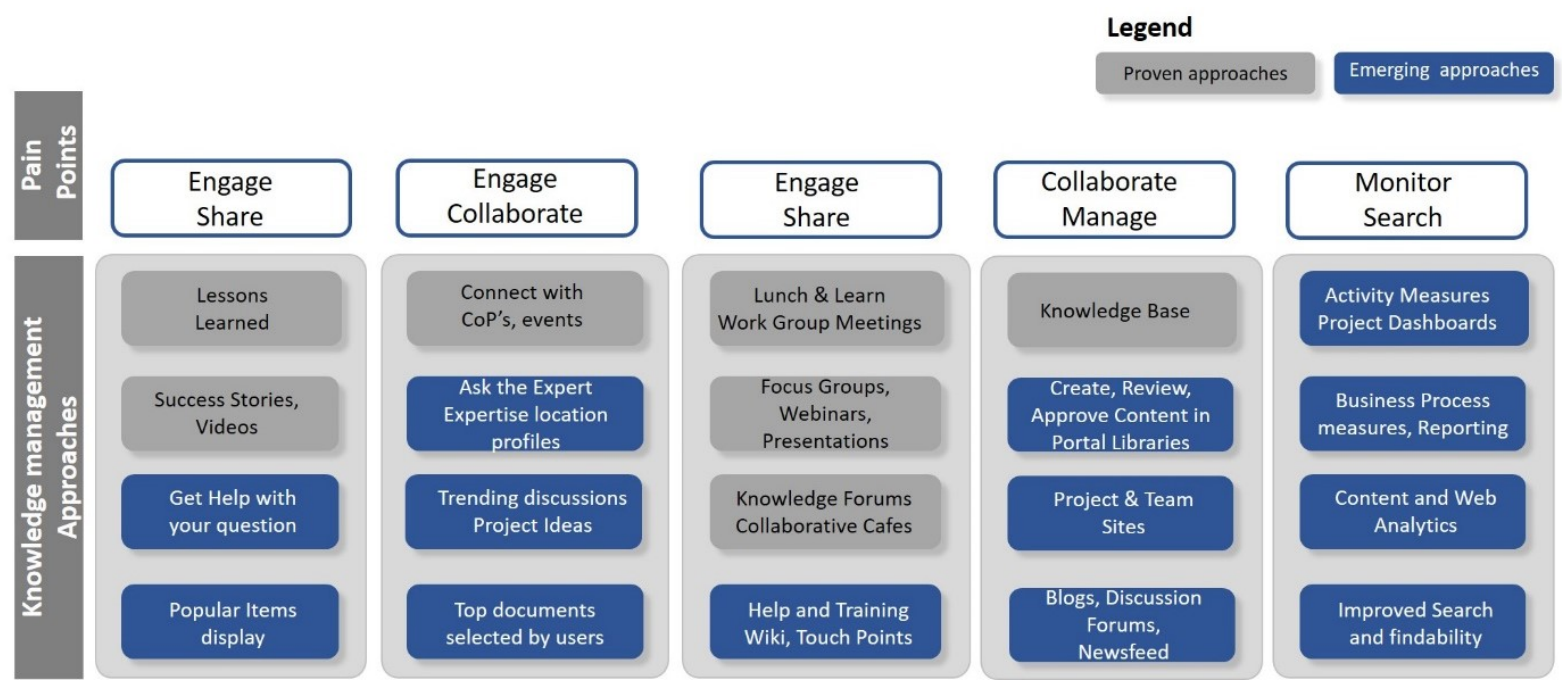

Figure 11: Proven and Emerging Knowledge Management Approaches Embedded within CS

\section{Conclusions}

Enhancing stakeholder engagement in digital transformation initiatives require robust process and peoplefocused foundations in order to be successful and sustainable. The strategies and blended solutions can include a wide range of permutations between the change management, knowledge management, and performance improvement domains. Organizations can achieve digital transformation while driving deeper engagement and better results for the business. Rebalancing mind and machine, platform and product, and core and crowd represent the future of the work and organizations. There are eight aspects that require continuous attention when leading these types of changes:

\subsection{People}

1. End User adoption - clearly explain the reason for the change and engage them through the entire change process and WIIFM (What's In It For Me) and business value.

2. Dynamic stakeholder engagement - stakeholders continue to be actively involved and responsive in the post- implementation phase, continuing to model adoption and business rules.

3. Create new working relationships - recognize the need to act and build competencies in users, as well as modeling the change with mentoring and coaching to make it work.

4. Workers' role changes - machine/technologies replace repetitive tasks in the flow; however, a set of skills remain the domain of people. Science, technology, engineering, and math are valuable for programming and decision making; Creativity - thinking outside the box to handle exceptions; Social skills - empathy, motivation, and interpersonal skills are crucial for managing information, decision making, and collaborative efforts. Physical dexterity - machines can dominate in the world of robots, but many jobs require dexterity that only human touch can achieve.

5. Managers' role changes - enable experimentation and data-driven decision making and help teams design good experiments and make fair and objective analyses that lead to the "best" answer; develop coach-like approaches for team members, developing them towards high performance and helping them build on their strengths and mitigate their weaknesses; set a context and vision for the team, and constantly work to align the workers to that vision.

\subsection{Processes}

1. Enhanced support model - be available to provide training; respond to questions; support learning at all levels (beginner, intermediate, advanced); make resources available to build and maintain trust and performance.

2. Value of feedback to optimize - be responsive to user feedback before, during and after implementation; demonstrate through follow-up updates and improvements that their input counts.

3. Continuously evaluate - evaluate what you do; capture gaps and opportunities.

Collaborative Sites were implemented in 23 departments, the corporate business area and few hospital administrations. This represents a limitation. If implemented organization-wide, more lessons learned could be 
drawn and the digital transformation strategy and roadmap adjusted accordingly. Collaborative Sites continue to evolve, driven by priorities in the organization, user identified needs, and progress in technology. This represents another limitation and challenge.

Next steps include analysis of the specific needs and development of a toolkit of templates that can be used across the CS users, automated workflows for repeated steps and Artificial Intelligence/Machine Learning to support users with their questions (chatbots, sentiment analysis). The challenges ahead relate to the constant rebalancing required to fine tune the digital transformation engine.

\section{Acknowledgements}

I would like to express my appreciation to Barbara Brady-Fryer, PhD, Senior Provincial Director, Knowledge Management, Marc Leduc, Senior Provincial Director, Health Evidence and Innovation, Patty Wickson, Executive Director, Innovation Evidence Evaluation and Impact, Provincial Clinical Excellence for sponsoring the collaborative site project, continuous mentoring, support and guidance. I want to thank the following colleagues from Knowledge Management Technology team for helping finalize the project and assist with implementation and post implementation: Moushir Elbishouty, PhD, Sr. Consultant, AbdAllah ElSheikh, MSc, Sr. Consultant, Bijan Farhoudi, MSc., Sr. Consultant, Jackie Sibilla, Consultant, Octavian Cismas, MLIS, Consultant, Tracey Ohrn, Consultant, Ellie Kim, MAS, Sr. Consultant, Ken Raeside, Sr. Consultant and Brianna Kopp, Sr. Consultant. I give special thanks to my family - Mihai, Ion, Florinuta and Nicolae - for always being there for me.

\section{References}

American Productivity Quality Centre (APQC). (2020) “Enhancing Employee Engagement in the Digital Workplace”, [online], American Productivity Quality Centre, Houston, TX, USA, https://www.apqc.org/resource-library/resourcelisting/enhancing-employee-engagement-digital-workplace

American Productivity Quality Centre (APQC). (2019) "Skills for Digital Workplace. White Paper", [online], American Productivity Quality Centre, Houston, TX, USA, https://www.apqc.org/resource-library/resource-listing/skills-digitalworkplace

American Productivity Quality Centre (APQC). (2018) "How to Engage Business Stakeholders in Knowledge Mapping", [online], American Productivity Quality Centre, Houston, TX, USA, https://www.apqc.org/resource-library/resourcelisting/how-engage-business-stakeholders-knowledge-mapping

American Productivity Quality Centre (APQC). (2019) “Delivering KM Value During Crisis and Chaos", [online], American Productivity Quality Centre, Houston, TX, USA Delivering KM Value During Crises and Chaos $\mid$ APQC

American Productivity Quality Centre (APQC). (2020) "Manage Employee Information and Analytics Key Benchmarks", [online], American Productivity Quality Centre, Houston, TX, USA Manage Employee Information and Analytics Key Benchmarks: Cross-Industry $\mid$ APQC

American Productivity Quality Centre (APQC). (2020) “Going (and Staying) Digital”, [online], American Productivity Quality Centre, Houston, TX, USA Going (and Staying) Digital: Making Digital Transformation a Reality $\mid$ APQC

American Productivity Quality Centre (APQC). (2020) "Building Your Knowledge Management Capabilities”, [online], American Productivity Quality Centre, Houston, TX, USA Building Your Knowledge Management Capabilities $\mid$ APQC

American Productivity Quality Centre (APQC). (2020) "Breaking the Barriers to Consider Knowledge Sharing", [online], American Productivity Quality Centre, Houston, TX, USA Breaking the Barriers to Knowledge Sharing | APQC

American Productivity Quality Centre (APQC). (2020) “Manage Employee Information and Analytics Key Benchmarks: Healthcare Industry", [online], American Productivity Quality Centre, Houston, TX, USA Manage Employee Information and Analytics Key Benchmarks: Healthcare Industry $\mid$ APQC

American Productivity Quality Centre (APQC). (2019) “Embrace KM's Role in Digital Transformation - and Don't Be Afraid to Take Ownership", [online], American Productivity Quality Centre, Houston, TX, USA Embrace KM's Role in Digital Transformation-and Don't Be Afraid to Take Ownership | APQC

Buytendijk, F., (2012) "Measurement Drives Behaviour", [online] Tableau Software https://www.oneas1a.com/PDF/Measurement Drives Behaviour.pdf

Dal Mas, F., Renaudin, M., Garlatti, A. and Massaro, M. (2018) Towards a Social Knowledge Management in a knowledgeintensive public organization, Proceedings of the 15th International Conference on Intellectual Capital, Knowledge Management And Organisational Learning ICICKM 2018, Academic Conferences and Publishing International Limited, Reading, pp. 40-48

Dickson, G. and Lindstrom, R.R. (2010) System transformation: Leads in a caring environment, leadersforlife | Victoria, BC, Canada, [online], https://insite.albertahealthservices.ca/main/assets/hr/tms-hr-learning-leads-booklet-systemstransformation.pdf

International Data Corporation (IDC). (2019) “Direct Digital Transformation Investment Spending to Approach 2020 and 2023; IDC Reveals 2020 Worldwide Digital Transformation Predictions”, [online], IDC https://www.idc.com/getdoc.jsp?containerld=prUS45617519 
International Data Corporation (IDC). (2021) "Future Enterprise: Building Resiliency To Thrive in the New Normal”, [online], IDC https://www.idc.com/events/futurescape

Gartner.(2020) "IT Roadmap for Digital Business Transformation", [online], Gartner

https://emtemp.gcom.cloud/ngw/globalassets/en/information-technology/documents/insights/the-gartner-it-roadmapfor-digital-buisness-transformation-excerpt.pdf

Green, A. (2013) Making It Real: Sustaining Knowledge Management, Adapting for Success in the Knowledge Based Economy, Academic Conferences and Publishing International Limited, UK.

Hubert, C. and Trees, L. (2016) "Breaking Barriers and Influencing Behaviours. Steps towards a Knowledge Sharing Culture", American Productivity Quality Council, Houston, TX, USA, Presentation at KM Conference.

Kane, G.C., Palmer, D., Phillips, A.N., Kiron, D., Buckley, N., (2015) "Strategy, not

Technology, Drives Digital Transformation", Deloitte , [online], 15-MIT-DD-Strategy.indd (deloitte.com)

Kavanaugh, J., Tarafdar, R., (2021, May) “Break Down Change Management into Small Steps”, HBR, [online], Break Down Change Management into Small Steps (hbr.org)

Kotter International. (2015) 8 Steps to Accelerate Change, [online], http://www.kotterinternational.com/ebook/eBookFinal-Copyright-2015.pdf

Lazar, J.B., Greenblatt, E., and Robu, D. (2017, September). Multiple root causes and blended solutions. Pre-conference workshop at ISPI EMEA Conference, Bologna, Italy.

Lazar, J.B. and Robu, D. (2015) “Accelerating the Development of Learning Organizations: Shifting Paradigms from Current Practice to Human Performance Improvement", Theoretical and Applied Economics, XXII, Vol. 1, No. 602, pp. 259274.

Leaders for Life. (2010) "System Transformation. The Root of the Matter: What Every Health Leader Should Know" [Executive Summary], [online], http://chlnet.ca/wpcontent/uploads/LEADS SystemsTrans ExecutiveSummary EN.pdf

McAfee, A., Brynjolfsson, E., (2017), "Machine, Platform, Crowd: Harnessing Our Digital Future", W.W.Norton \&Company Malopinsky, L.V. and Osman, G. (2006) "Dimensions of Organizational Change", In J.A. Pershing (Ed.), Handbook of Human Performance Technology, ( ${ }^{\text {rd }}$ Ed.), Pfeiffer, San Francisco, CA, USA, pp. 262-286.

McCauley, C. and Fick-Cooper, L. (2015) Direction, Alignment, Commitment: Achieving Better Results through Leadership. CCL Press, Greensboro, NC, USA.

O'Dell, C. and Trees, L. (2018) "KM in the Era of Digital and Smart Technologies", [online], American Productivity Quality Centre, Houston, TX, USA, https://www.apqc.org/resource-library/resource-listing/km-era-digital-and-smarttechnologies

Phillips, P.P., Phillips, J.J., Stone, R.D. and Burkett, H. (2007) The ROI Field Book. Butterworth-Heinemann, Burlington, MA, USA.

Robu, D. and Lazar, J.B. (2016, September) “Innovative Approach to a Virtual Collaboration Platform”, Bonn, Germany, Presentation at ISPI EMEA conference.

Rosenberg, S. and Mosca, J. (2011) “Breaking Down the Barriers to Organizational Change", International Journal of Management \& Information Systems, Vol. 15, No. 3.

Sousa, M.J. (2010), "Dynamic knowledge: An Action Research Project", The International Journal of Knowledge, Culture and Change Management, Vol. 10 No. 1, pp. 317-331.

Tabrizi, B., Lam Ed., Girard, Kirk., Irvin, Vernon., (2019) “Digital Transformation Is Not About Technology”, [online], Harvard Business Review https://hbr.org/2019/03/digital-transformation-is-not-about-technology

Van Tiem, D.M., Moseley, J.L., and Dessinger, J.C (2012) Fundamentals of Performance Improvement through People, Processes, and Organizations. ISPI Wiley, San Francisco, CA, USA 